\title{
Computer-Aided Design of Active Packaging/Food System for extended shelf life
}

\author{
Míriam R. García ${ }^{1, *}$ and Miguel Mauricio-Iglesias ${ }^{2, *}$ \\ * Equal contributors \\ ${ }^{1}$ Process Engineering, IIM-CSIC, Vigo, Spain, miriamr@iim.csic.es, \\ 2 Department of Chemical Engineering, Universidade de Santiago de Compostela, Spain, \\ miguel.mauricio@usc.es
}

\begin{abstract}
Common dynamic models of active packaging are focused on the mass transfer of the antimicrobial agents. Nevertheless, the interaction of the antimicrobial agent with the food microorganisms is usually neglected, despite being critical to optimise the food safety and quality.

In this work, we propose a dynamic model simulating the dynamics of carvacrol and its inhibition by Listeria monocytogenes in an active packaging system. Carvacrol is an antimicrobial agent allowed as a food additive and Listeria monocytogenes is the major psychrotrophic pathogen in food. The model can be exploited to study different aspects of the food quality and safety, such for example the maximum load of Listeria before packaging and the concentration of carvacrol to guarantee food quality and safety standards.
\end{abstract}

Keywords: Active packaging, Predictive microbiology, carvacrol inhibition, Listeria monocytogenes, optimal design

\section{INTRODUCTION}

The traditional role of packaging (containment, protection and dosing of food) has steadily been superseded by the use of the so-called active packaging. These innovative food packaging technologies allow to keep a steady level of moisture and oxygen, control pathogenic and spoilage microorganisms in food or even providing information to the consumer [23]. As a consequence of the multiple functions assumed by active packaging, its design and performance prediction becomes challenging. Mathematical models are especially suitable as tools for decision-support and risk assessment of novel active packaging formulations [19].

A model of active packaging combining microbial and antimicrobial dynamics is critical to maximising food quality while guaranteeing food safety standards. This model is especially relevant in seafood products where food safety and quality depend mainly on pathogenic and spoilage bacteria $[16,13]$. Even standard biochemical indexes, function of early quality attributes, highly depend on bacterial dynamics [26]. Moreover, the antimicrobial agent itself can be a source of organoleptic rejection when its flavour is unpleasant or hide the expected food taste at significant concentrations.

From the authors' knowledge, only the model by Kurek [18] has coupled mass transfer models with models of microbial dynamics for active packaging. In this work, the predictive microbiology model considers that the growth velocity dependent on the antimicrobial agent (allyl isothiocyanate), but only at isothermal conditions around $20^{\circ} \mathrm{C}$.

In this work, we extend the modelling framework to study non-isothermal conditions and formulate the design problem as a nonlinear programming optimisation. We illustrate the proposed framework in a case study consisting of the design of an active polypropylene (PP) packaging capable of inhibiting the growth of Listeria monocytogenes by controlling the release of carvacrol into a seafood matrix. Carvacrol (5-Isopropyl-2methylphenol) is an accepted food additive with antimicrobial properties and the primary component of essential oils [5, 4]. Listeria monocytogenes is the major psychrotrophic pathogen in food, causing Listeriosis, a life-threatening illness in immunocompromised and pregnant women.

\section{MODELING THE ACTIVE PACKAGING SYSTEM}

Mass transfer across polymeric food packaging takes place mainly by diffusion. A mass balance at unsteady state combined with Fickean diffusion, i.e. diffusivity is independent of solute concentration [21], leads to the following equation:

$$
\frac{\partial C_{P P}}{\partial t}=D \frac{\partial^{2} C_{P P}}{\partial x^{2}} \text { for } t>0 \text { and } 0<x<H
$$

where $C_{P P}$ is the concentration of carvacrol $\left(\mathrm{kg} / \mathrm{m}^{3}\right)$ and $\mathrm{D}$ is the diffusivity of carvacrol in PP $\left(m^{2} / s\right)$. This equation can be solved by defining the initial concentration

$$
C_{P P}(x, 0)=C_{P P, 0}
$$


and boundary conditions of no flux to outer environment:

$$
\left.\frac{d C_{P P}}{d x}\right|_{(0, t)}=0
$$

and known flux to the food:

$$
\left.D \frac{d C_{P P}}{d x}\right|_{(H, t)}=k_{L} a\left(C_{L}^{*}(t)-\left.C_{P P}\right|_{(H, t)}\right) .
$$

Here $k_{L}$ is the mass transfer coefficient in the packaging/food interface $(\mathrm{m} / \mathrm{s})$ and $a$ is the specific exchange area, defined as:

$$
a=\frac{A}{V_{L}}=\frac{\text { exchange area }}{\text { liquid volume }} \text {. }
$$

The concentration of carvacrol in the food bulk is determined by a mass balance:

$$
\frac{d C}{d t}=-k_{L} a\left(C^{*}(t)-\left.C_{P P}\right|_{(H, t)}\right) .
$$

with

$$
C^{*}=C K,
$$

being $\mathrm{K}$ the partition coefficient defined as

$$
K=\frac{C_{P P}^{\infty}}{C^{\infty}} .
$$

Diffusivity changes with temperature are modeled by an Arrhenius-like dependence:

$$
D(T)=D\left(T_{\text {ref }}\right) \exp \left(-\frac{E_{A}}{R}\left(\frac{1}{T}-\frac{1}{T_{\text {ref }}}\right)\right)
$$

where (see Table 1 for details) $E_{A}$ is the activation energy $(\mathrm{J} / \mathrm{mol}), R$ is the ideal gas constant $(J / \mathrm{mol} / K)$ and $T$ is the temperature $(K)$.

Tabla 1: Mass transfer parameters for carvacrol/PP at $298 \mathrm{~K}$ unless otherwise specified

\begin{tabular}{cccc} 
Parameter & Value & Units & Ref. \\
\hline$D$ & $3.0 \cdot 10^{-15}$ & $\mathrm{~m}^{2} / \mathrm{s}$ & {$[7]$} \\
$E_{A}$ & $1.27 \cdot 10^{5}$ & $\mathrm{~J} / \mathrm{mol}$ & {$[7,17]$} \\
$K$ & 124 & $\frac{\mathrm{m}^{3} \text { oood }}{\mathrm{m}^{3} \mathrm{PP}}$ & {$[8]$} \\
$k$ & $5.0 \cdot 10^{-3}$ & $\mathrm{~m} / \mathrm{s}$ & {$[20]$} \\
$H$ & $35 \cdot 10^{-6}$ & $\mathrm{~m}$ & - \\
$a$ & 60 & $\mathrm{~m}^{-1}$ & {$[11]$}
\end{tabular}

\section{MODELLING THE FOOD SYSTEM}

The objective is to model Listeria inhibition with carvacrol at non-isothermal conditions. In food microbiology, predictive microbiology models are well established with ad-hoc software tools for non-isothermal conditions. Nevertheless, they are not so usual for antimicrobial inhibition.
Primary models describe the growth dynamics of the microbial population. Baranyi [3] proposed the standard for a primary model that in the mathematical form described in [13] reads:

$$
\frac{d y(t)}{d t}=\frac{a_{0}}{a_{0}+\left(1-a_{0}\right) \exp (-\mu t)} \mu\left(1-10^{y(t)-y^{*}}\right)
$$

where $y$ is the logarithm of the colony-forming units per millilitre $(\mathrm{cfu} / \mathrm{ml})$ in a population. Assuming that one viable cell forms one colony, this state represents the concentration of viable cells in a population in logarithm scale. The model describes three phases: lag phase of adaptation when $a_{0}<1$, exponential growth with velocity $\mu$ and a stationary phase with the maximum density of viable cells represented by $y^{*}$.

We should stress that the limits established by EFSA (the European Food Safety Authority) for Listeria monocytogenes are so low that only the lag and exponential phase are useful for designing the active packaging. On the other hand, lag phase depends on numerous factors which make especially challenging to derive predictions. Moreover, population numbers are low and stochastic processes become relevant.

In this work, we assume that cells are fully adapted, and there is no lag phase $\left(a_{0}=1\right)$. This case represents the worst-case scenario, and safest one, and allows the use of a deterministic model for the exponential phase, even when population numbers are low [14]. Therefore the operational primary model reads:

$$
\frac{d y(t)}{d t}=\mu
$$

Secondary models define how parameters in primary model depend on different stress factors, in this work temperature $T$ and carvacrol concentration $C$. The dependence of Listeria monocytogenes with temperature has been widely studied, with most works using the cardinal temperature model [24]:

$$
\begin{gathered}
\mu=\mu_{o p t} \cdot \gamma_{T} \quad \text { with } \\
\gamma_{T}=\frac{\left(T-T_{-}\right)\left(T-T_{-}\right)^{2}}{\left(T_{*}-T_{-}\right)\left[\left(T_{*}-T_{-}\right)\left(T-T_{*}\right)-\left(T_{*}-T_{+}\right)\left(T_{*}+T_{-}-2 T\right)\right]}
\end{gathered}
$$

for $T_{-}<T<T_{+}$and zero otherwise. Here $\mu_{o p t}$ is the maximum growth at temperature $T_{*}$ and $T_{-}$ and $T_{+}$determines the range of growth.

Secondary models of antimicrobial effect, nevertheless, are scarce and very limited [12]. Usually, the parameters of the primary models $\left(\mu, a_{0}\right.$ or $\left.y^{*}\right)$ are estimated for different antimicrobial concentrations, but without finding a relationship that can be used for predicting or optimising the system. For this work we will use one of the few mod- 
els available,named the square root model [10]:

$$
\begin{aligned}
\mu & =\mu_{\text {opt }} \gamma_{C} \\
\gamma_{C} & = \begin{cases}\left(1-\frac{C}{M I C}\right)^{2}, & C<M I C \\
0 & C \geq M I C\end{cases}
\end{aligned}
$$

where $M I C$ is the minimum inhibitory concentration of carvacrol.

Therefore the final model reads

$$
\frac{d y(t)}{d t}=\mu=\mu_{o p t} \gamma_{T} \gamma_{C}
$$

with the $\gamma$ functions defined in (7) and (9). Table 2 shows the parameters of the operational predictive microbial model of Listeria monocytogenes inhibition with carvacrol.

Tabla 2: Parameter values defining the growth velocity of Listeria monocytogenes at nonisothermal conditions and under inhibition by carvacrol. The optimal growth $\mu_{\text {opt }}$ corresponds with the estimations for seafood.

\begin{tabular}{cccc} 
Parameter & Value & Units & Ref. \\
\hline$\mu_{\text {opt }}$ & 1 & $1 /$ hour & {$[1]$} \\
$T_{-}$ & -2.7 & ${ }^{\circ} \mathrm{C}$ & {$[2]$} \\
$T_{*}$ & 38.7 & ${ }^{\circ} \mathrm{C}$ & {$[2]$} \\
$T_{+}$ & 42.3 & ${ }^{\circ} \mathrm{C}$ & {$[2]$} \\
$\mathrm{MIC}$ & 0.37 & $\mathrm{Kg} / \mathrm{m}^{3}$ & {$[22]$}
\end{tabular}

\section{Optimal design of Active Packaging/Food System}

In this section, we exploit the developed model of carvacrol inhibition of Listeria in a standard active packaging system to maximise food quality while assuring food safety standards. Note that the carvacrol concentration $C$ and temperature $T$ are the variables connecting the food model with the active packaging model. $C$ is the output of the active packaging to the food model and depends on the carvacrol concentration in the packaging active polypropylene $\left(C_{P P}\right) . T$ is an input to both models and represents the storage temperature.

Food safety is quantified following EFSA recommendations. EFSA established that the maximum concentration of Listeria monocytogenes cannot exceed $100 \mathrm{cfu} / \mathrm{g}$ during the product shelf-life [9]. Let us assume that 1 gram of food approximates 1 millilitre. Therefore, per any millilitre of product juice the numbers of viable cells have to be less than 100 viable cells, i.e.:

$$
y(t)<2 \quad \text { for } \quad t<t_{f}
$$

where $t_{f}$ is the product shelf-life or final time for the model simulation. Therefore the shelf-life is defined based on the safety criterion using the Listeria bacteria as the reference.

Food quality is a complex, and usually subjective, attribute that depends mostly on spoilage seafood bacteria. In this preliminary approximation of the problem, we assume that the inhibition of spoilage bacteria is sufficiently relevant to obtain a product with enough quality. We should note that this assumption is supported by the fact that the growth of the spoilage bacteria is also inhibited by controlling the growth of Listeria. We expect in future works to add different quality indexes to the optimisation problem such as the $K$ index. This index is a relationship between different degradation compounds of adenosine triphosphate (ATP) that are linked with fish freshness at early storage stages. To this objective we need to adapt the dynamic model in the literature $[15,25,26]$ to include the inhibition effect of carvacrol to the spoilage bacteria.

The only quality index considered in this work is a limit of the carvacrol concentration in the food matrix. Listeria growth can be completely inhibited by using carvacrol concentrations in food larger than the so-called Minimum Inhibitory Concentration (MIC). Unfortunately, MICs have a negative impact on sensory properties [6]. That is especially relevant in antimicrobial agents like carvacrol with a pungent, warm odour characteristic of oregano [5]. Therefore we will require a concentration of carvacrol less than $0.3 \mathrm{Kg} / \mathrm{m}^{3}$ in the food matrix as the quality constraint

$$
C(t)<0.3 \quad \text { for } \quad t<t_{f}
$$

Food quality and safety, in the terms here defined, depends on the product conditions: in this work, we will focus on the concentration of carvacrol in the active packaging $\left(C_{P P}\right)$ and the storage temperature. As an example of the potential of the proposed model, we define in the next sections two optimisation problems of interested in the food industry.

\subsection{MAXIMUM LIMITS OF Listeria BEFORE PACKAGING}

In this case study we exploit the model to determine the maximum concentration of Listeria allowed to meet the EFSA recommendation $(y(t)<$ 2 ). Industry should have sampling-plans to assure that limits are met during the product shelf-life. A critical time during the sampling-plan is just before the packaging. This corresponds in the model with the initial time $t_{0}$ and, hence, the optimiza- 
tion problem reads:

$$
\begin{aligned}
\max _{y\left(t_{0}\right)} & y\left(t_{0}\right)^{2} \\
\text { s.t. } & y\left(t_{f}\right)<2
\end{aligned}
$$

where last constrain is equivalent to meet the EFSA recommendation along the shelf life $(y(t)<$ 2 ), since $y(t)$ is a monotonically increasing function.

Table 3 shows the results obtained for different conditions. We start solving the optimisation problem for a refrigerated product $\left(T=-1^{\circ} C\right)$ without carvacrol concentration. We note that the maximum Listeria concentrations should be of less than 33 cells $/ \mathrm{ml}$ for a product of 10 days in the market, while concentrations are of 71 cells $/ \mathrm{ml}$ for a product with only 3 days of shelf-life.

Tabla 3: Maximum limits of Listeria before packaging to meet EFSA recommendations

\begin{tabular}{ccc|c}
\multicolumn{3}{c|}{ Conditions } & Limit \\
Shelf-life & $C\left[\mathrm{Kg} / \mathrm{m}^{3}\right]$ & $T\left[{ }^{\circ} \mathrm{C}\right]$ & $y\left(t_{0}\right)[c f u / m l]$ \\
\hline 3 days & 0 & -1 & 71.71 \\
5 days & 0 & -1 & 57.45 \\
10 days & 0 & -1 & 33.00 \\
\hline 3 days & 0 & 5 & 0 \\
5 days & 0 & 5 & 0 \\
10 days & 0 & 5 & 0 \\
\hline 3 days & 50 & 5 & 88.37 \\
5 days & 50 & 5 & 88.12 \\
10 days & 50 & 5 & 87.66
\end{tabular}

That picture changes entirely if the product is not correctly refrigerated $\left(T=5^{\circ} \mathrm{C}\right)$. In this case, there cannot be even one cell $/ \mathrm{ml}$. If there is, it will grow and proliferate until levels higher than the ones recommended by EFSA. This case is a significant problem for the industry since there are not detection methods with such a low limit of detection (LOD). In other words, there are no methods that can reliably testify that a millilitre of food juice is utterly free of pathogens.

In the last stage, we illustrate how active packaging works to maintain safety levels even when the product is not correctly refrigerated. Assuming the concentration of carvacrol in the active packaging is of $50 \mathrm{~kg} / \mathrm{m}^{3}$, Listeria concentrations before packaging can be allowed whenever the limits in the table are met.

We should stress that this simple optimisation is relevant, not only to detect risks but to determine the appropriate method of detection ofListeria. There are different methods with different limits of detection in the market (LOD). Therefore, for example, a method with a LOD of $80 \mathrm{cfu} / \mathrm{ml}$ is sufficient for the case of an active packaging with carvacrol stored at a temperature of $5^{\circ} \mathrm{C}$. However, more sensitive methods are needed, with a LOD of $70 \mathrm{cfu} / \mathrm{ml}$, for the case of a correctly refrigerated food without carvacrol.

\subsection{OPTIMAL DESIGN TO MAXIMIZE SHELF-LIFE SATISFYING FOOD QUALITY AND SAFETY SPECIFICATIONS}

Shelf-life $\left(t_{f}\right)$ depends on food quality and safety standards. In this case study, we design the carvacrol concentration in the active packaging and the product shelf-life to maximize last variable $\left(t_{f}\right)$ while following EFSA recommendations and with concentrations of carvacrol in food less than $0.3(C(t)<0.3)$ Formal optimization problem reads:

$$
\begin{aligned}
\max _{t_{f}, C_{\text {pack }, 0}} & t_{f}^{2} \\
\text { s.t. } & y\left(t_{f}\right)<2 \\
& C\left(t_{f}\right)<0.3
\end{aligned}
$$

with bound for shelf-life of $t_{f} \in(0,30]$ days and for carvacrol of $C_{\text {pack,0 }} \in[0,1000] \mathrm{Kg} / \mathrm{m}^{3}$.

Figure 1 shows the results of the optimisations at different temperatures of storage. We can distinguish three stages: at low, medium and high temperatures.

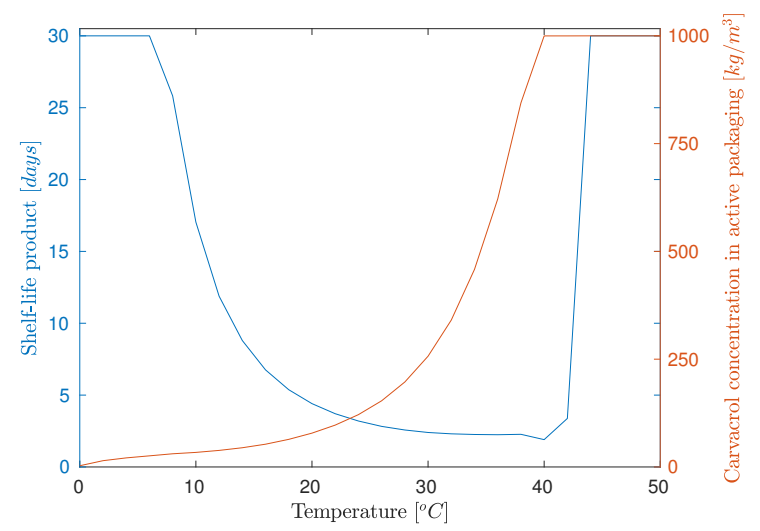

Figura 1: Maximum shelf-life to follow EFSA recommendations while maintaining organoleptic standards (avoid large concentrations of carvacrol in the food matrix).

At low temperatures (less than $10^{\circ} \mathrm{C}$ ), a product shelf-life of 30 days, the maximum allowed in the optimisation, meets the EFSA recommendations. As temperature increases, the concentration of carvacrol have also to increase in the PP, but always using values lower than the limit.

At medium temperatures, the product shelf-life is less than 30 days. The algorithm calculates the 
maximum shelf-life to maintain the limits of Listeria using the maximum concentration of carvacrol without exceeding the limit of $0.3 \mathrm{Kg} / \mathrm{m}^{3}$ in the food matrix. The minimum shelf-life is obtained at around $38^{\circ} \mathrm{C}$, the optimum temperature of growth $\left(T_{*}\right)$ of Listeria in equation (7).

At temperatures larger than this optimum, Listeria cannot sustain growth so shelf-life starts again to increase.

\section{CONCLUSIONS}

In this work we propose a model to simulate an active packaging where Listeria monocytogenes is inhibited with carvacrol at non-isothermal conditions.

We design two optimisation problems that illustrate the relevance of this type of models. In the first optimisation problem, we calculate the maximum concentration of Listeria allowed during packaging to meet the EFSA recommendations along the product life. In the second case study, we optimise carvacrol concentration in the active packaging to maximising shelf-life of the product at different temperatures. The approach also allows considering time-varying profiles of temperature to simulate different expected storage conditions along the food chain.

\section{Acknowledgements}

M.R.G acknowledges financial support from the Spanish Government (MINECO) and the European Regional Development Fund (ERDF) through the project "RESISTANCE" (DPI2014-54085-JIN). M.M.I belongs to the Galician Competitive Research Group GRC2013032 and the CRETUS strategic partnership (AGRUP2015/02), co-funded by FEDER (EU).

\section{References}

[1] J. C. Augustin and V. Carlier. Mathematical modelling of the growth rate and lag time for Listeria monocytogenes. International Journal of Food Microbiology, 56(1):29-51, 2000. doi: 10.1016/S0168-1605(00)00223-3.

[2] S. Bajard, L. Rosso, G. Fardel, and J. P. Flandrois. The particular behaviour of Listeria monocytogenes under sub-optimal conditions. International Journal of Food Microbiology, 29(2-3):201-211, 1996 . doi: 10.1016/0168-1605(95)00031-3.

[3] J. Baranyi and T. A. Roberts. A dynamic approach to predicting bacterial growth in food. International Journal of Food Microbiology,
23(3-4):277-294, 1994 doi: 10.1016/01681605(94)90157-0.

[4] C. M. Belda-Galbis, A. Leufvén, A. Martínez, and D. Rodrigo. Predictive microbiology quantification of the antimicrobial effect of carvacrol. Journal of Food Engineering, 141:37-43, 2014. doi: 10.1016/j.jfoodeng.2014.05.013.

[5] G. A. Burdock. Fenaroli's handbook of flavor ingredients. CRC press, 2010. doi: 10.1016/S0015-6264(76)80260-X.

[6] R. Cava, E. Nowak, A. Taboada, and F. Marin-Iniesta. Antimicrobial activity of clove and cinnamon essential oils against Listeria monocytogenes in pasteurized milk. Journal of food protection, 70(12):2757-63, 2007. doi: 10.4315/0362-028X-70.12.2757.

[7] J. Cerisuelo, V. Muriel-Galet, J. M. Bermúdez, S. Aucejo, R. Catalá, R. Gavara, and P. Hernández-Muñoz. Mathematical model to describe the release of an antimicrobial agent from an active package constituted by carvacrol in a hydrophilic EVOH coating on a PP film. Journal of Food Engineering, 110(1):26-37, 2012. doi: 10.1016/J.JFOODENG.2011.12.013.

[8] J. P. Cerisuelo, J. M. Bermúdez, S. Aucejo, R. Catalá, R. Gavara, and P. Hernándezmuñoz. Describing and modeling the release of an antimicrobial agent from an active $\mathrm{PP} / \mathrm{EVOH} / \mathrm{PP}$ package for salmon. Journal of Food Engineering, 116:352-361, 2013. doi: 10.1016/j.jfoodeng.2012.12.028.

[9] Commission of the European Communities. Commission Regulation (EC) No $2073 / 2005$ on microbiological criteria for foodstuffs. Official Journal of the European Union, pages L338, 1-26, 2005. URL https://eur-lex.europa.eu/ legal-content/EN/TXT/HTML/?uri=CELEX : 32005R2073\{\&\}from=EN.

[10] P. Dalgaard. Modelling of microbial activity and prediction of shelf life for packed fresh fish. International Journal of Food Microbiology, 26(3):305-317, 1995. doi: 10.1016/01681605(94)00136-T.

[11] EU Commission. Regulation (EC) No 852/2004. Technical Report May 2002, 2004. URL http://eur-lex.europa.eu/ LexUriServ/LexUriServ . do?uri=0J : L : 2004:139:0001:0054:en:PDF.

[12] M. R. García and M. L. Cabo. Optimization of $E$. coli Inactivation by Benzalkonium Chloride Reveals the Importance of Quantifying the Inoculum Effect on Chemical Dis- 
infection. Frontiers in Microbiology, 9:1259, 2018. doi: 10.3389/fmicb.2018.01259.

[13] M. R. García, C. Vilas, J. R. Herrera, M. Bernárdez, E. Balsa-Canto, and A. A. Alonso. Quality and shelf-life prediction for retail fresh hake (Merluccius merluccius). International journal of food microbiology, 208:65-74, 2015. doi: 10.1016/j.ijfoodmicro.2015.05.012.

[14] M. R. García, J. A. Vázquez, I. G. Teixeira, and A. A. Alonso. Stochastic individual-based modeling of bacterial growth and division using flow cytometry. Frontiers in Microbiology, 8:2626, 2018. doi: 10.3389 /fmicb.2017.02626.

[15] P. Howgate. A review of the kinetics of degradation of inosine monophosphate in some species of fish during chilled storage. 41(4):341-353, apr 2006. ISSN 09505423. doi: $\quad 10.1111 / \mathrm{j} .1365-2621.2005 .01077 . x$. URL http://doi.wiley.com/10.1111/j. 1365-2621.2005.01077.x.

[16] H. H. Huss. Assessment and management of seafood safety and quality. Number 444. Daya Books, 2007.

[17] M. Krepker, O. Prinz-setter, R. Shemesh, A. Vaxman, D. Alperstein, and E. Segal. Antimicrobial Carvacrol-Containing Polypropylene Films: Composition, Structure and Function. Polymers, 10:79, 2018. doi: 10.3390/polym10010079.

[18] M. Kurek, Y. Laridon, E. Torrieri, V. Guillard, A. Pant, C. Stramm, N. Gontard, and C. Guillaume. A mathematical model for tailoring antimicrobial packaging material containing encapsulated volatile compounds. Innovative Food Science \& Emerging Technologies, 42:64-72, 2017. doi: 10.1016/J.IFSET.2017.05.014.

[19] A. López-Gómez, P. S. Fernández, A. Palop, P. M. Periago, A. Martinez-López, F. MarinIniesta, and G. V. Barbosa-Cánovas. Food safety engineering: An emergent perspective. Food Engineering Reviews, 1(1):84-104, jun 2009. doi: 10.1007/s12393-009-9005-5.

[20] B. Martinez-Lopez, S. Peyron, N. Gontard, and M. Mauricio-Iglesias. Practical identifiability analysis for the characterization of mass transport properties in migration tests. Industrial $\&$ Engineering Chem- istry Research, 54(17):4725-4736, 2015. doi: 10.1021/ie505057a.

[21] M. Mauricio-Iglesias, V. Guillard, N. Gontard, and S. Peyron. Application of FTIR and Raman microspectroscopy to the study of food/packaging interactions. Food Additives and Contaminants - Part A Chemistry, Analysis, Control, Exposure and Risk Assessment, 26(11):1515-1523, 2009. doi: 10.1080/02652030903148306.

[22] I. E. Pol and E. J. Smid. Combined action of nisin and carvacrol on Bacillus cereus and Listeria monocytogenes. Letters in Applied Microbiology, 29(3):166-170, 1999. doi: 10.1046/j.1365-2672.1999.00606.x.

[23] S. Raouche, M. Mauricio-Iglesias, S. Peyron, V. Guillard, and N. Gontard. Combined effect of high pressure treatment and antimicrobial bio-sourced materials on microorganisms' growth in model food during storage. Innovative Food Science and Emerging Technologies, 12(4):426-434, 2011. doi: 10.1016/j.ifset.2011.06.012.

[24] L. Rosso, J. R. Lobry, S. Bajard, and J. P. Flandrois. Convenient model to describe the combined effects of temperature and $\mathrm{pH}$ on microbial growth. Applied and Environmental Microbiology, 61(2):610-616, 1995.

[25] C. Vilas, A. A. Alonso, J. R. Herrera, A. García-Blanco, and M. R. García. A model for the biochemical degradation of inosine monophosphate in hake (Merluccius merluccius). Journal of Food Engineering, 200:95-101, 2017. doi: 10.1016/j.jfoodeng.2016.12.016.

[26] C. Vilas, A. A. Alonso, J. R. Herrera, M. Bernárdez, and M. R. García. A mathematical model to predict early quality attributes in hake during storage at low temperature. Journal of Food Engineering, 222:11-19, 2018. doi: 10.1016/j.jfoodeng.2017.11.005.

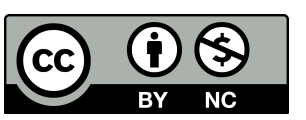

(c) 2018 by the authors. Submitted for possible open access publication under the terms and conditions of the Creative Commons Attribution CC-BY-NC 3.0 license (http://creativecommons.org/licenses/by-nc/3.0/). 